\title{
CULTURA JURÍDICA Y PROTECCIÓN DE LAS INVERSIONES EXTRANJERAS
}

\author{
Edgar Neira Orellana $\left(^{*}\right)$
}

\section{Introducción}

$\mathrm{Si}$ asumimos que la cultura es todo aquello que el hombre añade a la naturaleza con el fin de entretejer modos de vida, conocimientos, habilidades y cosmovisiones, debemos entender la cultura jurídica como aquellos instrumentos que se agregan al derecho natural y que tienden a hacer efectivo el ideal de justicia y los valores supremos del orden, la paz y la libertad.

Cada cultura jurídica para ser considerada tal deberá aceptar la existencia de otras distintas y crear mecanismos de comunicación entre sistemas legales diversos partiendo de la premisa de que la libertad y la paz, valores consustanciales a la convivencia civilizada, no son patrimonio de ninguna concepción del Derecho en particular. Pero, frente a los valores que defiende la cultura del Derecho tenemos los antivalores que buscan limitar sus expresiones. Me refiero a la incultura jurídica que niega la existencia de culturas diversas y promueve el ensimismamiento o el aislamiento de los sistemas legales.

El arbitraje de inversiones que conoce de conflictos surgidos entre sujetos de derecho privado -inversionistas- y Estados

(*) Doctor en Jurisprudencia y abogado de los tribunales de justicia del Ecuador, master en Derecho Administrativo por la Universidad San Francisco de Quito, catedrático de esta universidad y de la Universidad Pontificia Católica del Ecuador, árbitro de la Cámara de Comercio de Quito y del Centro Internacional de Arbitraje de la Cámara de Comercio Ecuatoriano Británico. Socio del Estudio Gallegos, Valarezo \& Neira y autor de varios artículos especializados de derecho público ecuatoriano. 
investidos de potestad soberana, es la expresión de una determinada cultura jurídica porque refleja el ideal de justicia en la protección del derecho humano de propiedad, del principio de la seguridad jurídica y de la buena fe en las decisiones que adopta el poder público con relación a una inversión extranjera. Adicionalmente, plantea un encuentro entre culturas jurídicas diversas, esto es, entre cosmovisiones que se revelan distintas al momento de implantar su ideal de justicia, porque los instrumentos que cada sistema crea para aplicar el Derecho y sus fuentes presentan un sinnúmero de contrastes.

La diversidad jurídica es un problema que debe resolver el arbitraje de inversiones, más aun cuando amenazas de incultura jurídica tratan de desconocer su idoneidad como método alternativo de resolución de disputas entre inversionistas y Estados. Estas amenazas quedaron en evidencia en tres acciones que referiré a continuación y que requieren especial atención de la doctrina y del juicio de los árbitros internacionales:

Mediante sentencia de 1 de agosto de 2002, la Sala de lo Contencioso Administrativo del Consejo de Estado de Colombia, en un caso relacionado con la construcción de una presa hidroeléctrica en el Caribe colombiano, resolvió anular ex officio un laudo expedido por un Tribunal Arbitral constituido bajo las normas de la Cámara de Comercio Internacional de París. Este episodio conocido como Caso Termorío fue un proceso al que la doctrina no ha escatimado palabras para descalificar tal sentencia como un golpe bajo al arbitraje internacional.

Cinco años más tarde, el 2 de mayo de 2007, el Ministerio de Relaciones Exteriores de la República de Bolivia denunció formalmente la Convención sobre Arreglo de Diferencias Relativas a Inversiones conocida como Convención de Washington. Varios meses después, la República del Ecuador, al amparo del Art. 25 numeral 4 de la Convención de Washington decidió sustraer de la jurisdicción de los tribunales de arbitraje del CIADI las cuestiones relativas a hidrocarburos. En junio de 2009, 
Ecuador denunció la Convención de Washington al igual que lo hizo Bolivia.

Estas tres acciones que comportan negación del arbitraje internacional y sus mecanismos, responden a causas distintas y corresponden a contextos diferentes. Pero si consideramos que el denominador común de tales acciones ha sido que los países que las desencadenaron tienen una tradición jurídica civilista continental, las preguntas que al respecto se plantean serían al menos dos: ¿Cuánto aporta la cultura jurídica de esos tres países a un eventual desencuentro con la del arbitraje internacional? ¿Los elementos que integran nuestra tradición jurídica civilista resisten $o$, al contrario, promueven mecanismos de solución de disputas con la intervención de tribunales internacionales de arbitraje?

Para responder tales interrogantes no me he propuesto agotar la extensa temática que sugiere el ambicioso título del presente análisis. Me limitaré a dejar sentados algunos elementos de una discusión que aspiro contribuyan a abordar temas específicos del arbitraje internacional y entender mejor algunas reacciones.

\section{EL ARBITRAJE DE INVERSIONES Y LA CONFLUENCIA DE FAMILIAS JURÍDICAS}

Si la inversión productiva es necesaria para generar empleo y desarrollar nuestras economías, ni se diga cuando los recursos propios escasean, la protección de las inversiones extranjeras exige de nuestros países seguridad jurídica y la confianza indispensables para el ingreso de capitales foráneos. Por esto, los conflictos que se generen con dichas inversiones requieren de instancias independientes y expeditas para resolverlos como lo es el arbitraje internacional.

Si se considera que en una controversia arbitral internacional convergen familias jurídicas diversas como las instituciones 
del common law, las prácticas procesales del sistema angloamericano y los aportes jurídicos derivados de la tradición romanogermánica, entre otros, una primera conclusión nos llevará a sostener que las culturas jurídicas no son líneas paralelas sino organismos vitalmente confluentes, porque han sido concebidas por seres humanos que se relacionan e intercambian más allá de las barreras erigidas por los Estados. El arbitraje de inversiones ofrece un extenso diálogo entre esas culturas jurídicas diversas y confirma la vocación ecuménica del hombre y del derecho natural.

El Art. 42 de la Convención de Washington que creó el Centro Internacional de Arreglo de Disputas Relativas a Inversiones ${ }^{1}$-identificado como CIADI por sus siglas en español-, señala que los arbitrajes se regirán por la ley que hubieren convenido las partes y si éstas nada hubieren acordado al respecto, por las normas de derecho del Estado parte de la controversia, incluyendo sus normas de derecho internacional privado $\mathrm{y}$, las del derecho internacional que pudieren ser aplicables.

Sobre la base de la norma comentada y, para avanzar en el análisis de la confluencia de culturas, debo referirme a cómo opera el sistema de fuentes en el Derecho Internacional de las Inversiones.

En el arbitraje internacional se suele citar como criterio enumerativo de fuentes, el del Art. 38 del Estatuto de la Corte Internacional de Justicia ${ }^{2}$ que señala las siguientes: las conven-

1. "Art. 42.- (1) El Tribunal decidirá la diferencia de acuerdo con las normas de derecho acordadas por las partes. A falta de acuerdo, el Tribunal aplicará la legislación del Estado que sea parte en la diferencia, incluyendo sus normas de derecho internacional privado, $\mathrm{y}$ aquellas normas de derecho internacional que pudieren ser aplicables; (2) El Tribunal no podrá eximirse de fallar so pretexto de silencio u obscuridad de la Ley; (3) Las disposiciones de los precedentes apartados de este Artículo no impedirán al Tribunal, si las partes asi lo acuerdan, decidir la diferencia en aequo et bono".

2. "Art. 38.- 1. La Corte, cuya función es decidir conforme al derecho internacional las controversias que le sean sometidas, deberá aplicar: a. Las convenciones intemacionales, sean generales o particulares, que establecen reglas expresamente reconocidas por los Estados litigantes; b. La costumbre internacional como prueba de una práctica generalmente aceptada como derecho; $\mathfrak{c}$. los principios generales de derecho reconocidos por las naciones civilizadas; $\mathbf{d}$. Las decisiones judiciales y las doctrinas de los publicistas de mayor competencia de las distintas naciones, como medio auxiliar para la determinación de las reglas de derecho, sin perjuicio de lo dispuesto en el Art. 59. 
ciones internacionales, la costumbre internacional, los principios generales del derecho, las decisiones judiciales y la doctrina como un medio auxiliar para la determinación de las reglas de derecho, en posición prevalente respecto del derecho interno del Estado parte de una controversia arbitral.

Para el arbitraje de inversiones, una fuente muy importante son los tratados de protección recíproca de inversiones ${ }^{3}$ y los tratados de libre comercio que incorporan capítulos relativos a la protección de las inversiones. Adicionalmente tenemos la costumbre internacional que ha aportado los contenidos de dichos tratados de protección. El jurista Fernando de Trazegnies destaca que el Derecho Consuetudinario Internacional es una fuente importante de lo que denomina el nuevo Derecho Transnacional de los Negocios, que ha venido evolucionando con prácticas centenarias y decantándose gracias a la reflexión de los tratadistas y la jurisprudencia de tribunales arbitrales internacionales ${ }^{4}$. $Y$ es en la costumbre como fuente de obligaciones jurídicas en la que identificamos una clave diferenciadora con nuestros sistemas basados en la ley escrita: el derecho de las inversiones es, ante todo, un producto de la costumbre internacional que ha venido fijando las bases de un trato mínimo a favor de los inversionistas extranjeros, mientras que en nuestros sistemas jurídicos los derechos ordinariamente nacen de la norma legal expedida por la función legislativa de los Estados.

2. La presente disposición no restringe la facultad de la Corte para decidir un litigio ex aequo et bono, si las partes así lo convinjeren".

3. Comúnmente identificados por sus siglas en inglés BITs (Bilateral Investments Treaties), Actualmente han sido suscritos más de 2,500 tratados de protección de inversiones y, aunque por sí mismos no provocan el efecto inmediato de incrementar el flujo de inversiones, sí constituyen un elemento condicional para afincar la seguridad jurídica y la confianza que propician la inversión extranjera.

4. Femando de Trazegnies Granda, "¿Lex Mercatoria Rediviva? Primera Parte: De la Edad Media a la Post-modernidad", articulo publicado en la Revista Peruana de Arbitraje No. 3, pp. 15-51, Lima, 2006. Una de las conclusiones del autor es que el comercio que se extendió durante la Edad Media configuró la denominada lex mercatoria, una regulación jurídica formada de prácticas que iban más allá de los derechos locales y tendían a la universalidad. En el mundo contemporáneo de los negocios, el derecho internacional de las inversiones resucita la esencia de la lex mercatoria que creó la costumbre de los comerciantes. 
En síntesis, si el Derecho Internacional de las Inversiones se crea y renueva en virtud de la espontaneidad del tráfico mercantil internacional, éste habrá roto la idea matriz sobre la que se han erigido nuestros sistemas legales en que el Estado se ha reservado para sí el monopolio en la creación del Derecho.

Con el paso del tiempo, estas bases de trato mínimo a los inversionistas extranjeros, han sido reconocidas en tratados bilaterales de protección de inversiones y en capítulos específicos de los Tratados de Libre Comercio. Por ejemplo, en el caso de la República del Ecuador que ha suscrito más de quince tratados de protección recíproca de inversiones, en el texto de éstos aparece aquello que el derecho consuetudinario internacional ha erigido como bienes jurídicos indispensables para proteger el flujo de capitales y que constituyen lo que se ha dado en denominar "estándares de protección": trato nacional, tratamiento de la nación más favorecida, trato justo y equitativo, no confiscación, libre transferencia de fondos y dividendos.

Dado que esos estándares no se sustentan en ninguna normativa previamente elaborada, la jurisprudencia sentada por tribunales arbitrales internacionales va cobrando una importancia no solo creciente sino arrolladora en la definición y alcance de estas materias. Así, en esta segunda fuente encontramos otro elemento diferenciador con nuestros sistemas civilistas: la importancia que el arbitraje internacional de las inversiones asigna a la jurisprudencia para definir el contenido de cada uno de esos estándares, cuya aplicación a los casos que se someten a la decisión arbitral ha ido conformando un cuerpo de precedentes reiteradamente citados por los abogados que defienden casos ante tribunales del CIADI o UNCITRAL y en las decisiones adoptadas por dichos tribunales.

En este punto es de subrayar que en el sistema del CIADI, ninguna norma de la Convención de Washington ha establecido que los laudos de un Tribunal sean vinculantes respecto a los que posteriormente se expidan sobre el mismo punto de derecho.

156 Revista Ecuatorlana de Arbitraje 
No existe el stare decisis de la familia jurídica anglosajona, que imponga un acatamiento obligatorio de laudos precedentes. Sin embargo, la jurisprudencia arbitral internacional es una fuente importante en el derecho internacional de las inversiones $y$, por este motivo, los árbitros bajo el sistema del CIADI acostumbran a citar en sus decisiones pronunciamientos de otros tribunales.

A este respecto, el laudo emitido en el caso El Paso Energy International Company contra República Argentina, el panel arbitral resolvió:

"39. Los Tribunales Arbitrales del CIADI se establecen ad hoc, para cada caso, en el marco del Convenio de Washington. El presente Tribunal no tiene conocimiento de la existencia de ninguna disposición, ya sea en dicho Convenio o en el TBL, por la que se establezca la obligación de stare decisis, sin embargo, es razonable suponer que los tribunales de arbitraje internacionales, sobretodo los creados dentro del sistema CIADI, en general tendrán en cuenta los precedentes establecidos por otros órganos arbitrales $y$ en especial por otros tribunales internacionales..." 5 .

Por tanto, no puede desconocerse la fuerza que van cobrando los laudos internacionales como fuente del derecho internacional de las inversiones.

Jan Paulsson destaca que en la década pasada en que se expandió el arbitraje de inversiones, las posibilidades de laudos inconsistentes o contradictorios pudo ser mayor, pues ese período correspondió a una etapa de maduración del arbitraje de inversiones. Pero que a partir de este momento vendrá una segunda generación de laudos "cuyas principales características serán la consolidación de las tendencias dominantes, la reducción progresiva de desconcertantes diferencias entre los laudos y, en consecuencia, laudos más consistentes" 6 .

5. EI Paso Energy International Company vs. República Argentina, Caso ARB/03/15, www.worldbank.org/icsid/cases/ARB0315-DOJ-S.pdf, citado por Fernando Cantuarias en su obra "Arbitraje Comercial y de las Inversiones", Ed. Universidad Peruana de Ciencias Aplicadas, Lima, 2007 , página 758 .

6. Jan Paulsson, ¿Cómo mejorar los laudos intemacionales sin minar el sistema?, publicado en Revista Peruana de Arbitraje, Nưmero 8, Lima, 2009, p. 12. 
Edgar Neira Orellana

\section{ALGUNAS CARACTERÍSTICAS DE LOS SISTEMAS JURÍDICOS DE TRADICIÓN ROMANO-GERMÁNICA}

Para sondear en los basamentos de los regímenes jurídicos latinoamericanos me referiré a dos circunstancias que considero definitivas en la estructuración de sus sistemas legales y en la consolidación de una cultura jurídica: la primera está relacionada con el proceso codificador llevado adelante por Napoleón que, a partir de 1804, aspiraba a abreviar la razón ordenadora en un Código; la segunda, con la irrupción del positivismo jurídico, principalmente el de carácter analítico de inicios del siglo XX con la publicación de la obra "Teoría Pura del Derecho" del jurista austríaco Hans Kelsen?

El modelo codificador francés que irradió en los países europeos continentales $y$, posteriormente, en el derecho de los países latinoamericanos se ha sustentado en las ideas expuestas por Montesquieu en su obra "El espiritu de las Leyes" en la que destacó la ley como expresión de la voluntad general, promulgada por los órganos legislativos de un Estado que reservaba para sí la capacidad exclusiva de interpretar la voluntad general y, consecuentemente, el monopolio de la creación del Derecho. Así fue como la cultura jurídica continental europea empezaba fatalmente a dar la espalda al iusnaturalismo.

Ciento cincuenta años más tarde, el positivismo dará el golpe de gracia definitivo al iusnaturalismo contractualista $\mathrm{y}$, desde luego, a la costumbre como fuente primaria del derecho puesto que la razón para crearlo se convirtió penosamente en mero instrumento de su interpretación. Me refiero al jurista Kelsen que introdujo la preocupación del origen y la validez de la ley: cuál es el organo competente para expedirla y cuáles las condiciones de su vigencia y derogatoria, serán las preguntas que tratará de responder este autor y para ello objetará cualquier

7. Sobre este tema es de lectura recomendada la obra de Mauricio A. Plazas Vega, "Ideas politicas y teoria del derecho", Ed. Temis y Universidad del Rosario, Bogotá 2003. 
explicación metafísica que no esté basada en la ley. En su célebre análisis sobre el "deber ser", dio lugar a un desmedido culto a las normas legales y limitó a los juristas a un mundo fantástico, idealizado, separado de la realidad. El discurso kelseniano sobre las normas, su jerarquía y validez conserva un reconocido liderazgo en el pensamiento jurídico latinoamericano y se ha constituido en el sustrato de los regímenes legales de nuestros países.

Frente a estos eventos históricos que consolidaron un Derecho originado en el Estado y dejaron de lado los principios universales del derecho natural, no podemos desconocer que las economías de los países, a despecho de sus regímenes legales, se relacionan permanentemente y que el tráfico mercantil supera las barreras artificiales creadas por los sistemas legales de cada Estado. Esto ha dado origen a la suscripción de tratados internacionales entre Estados para proteger la inversión extranjera y la adopción de mecanismos alternativos de solución de disputas, independientes de los Estados. Por ello, cuando se trata de una inversión extranjera protegida por un tratado internacional, la eventual controversia no necesariamente se resolverá con la aplicación de las normas del derecho interno. Si la actuación del Estado violenta compromisos asumidos en un Tratado de Protección de Inversiones, el Derecho Administrativo Interno no es aplicable en la solución del conflicto, porque a un panel arbitral internacional le resultará indiferente si la actuación violatoria de obligaciones internacionales fue o no conforme a las normas del Derecho Público interno.

Por ello, los conceptos e instituciones del contencioso administrativo local poco tienen que ver ante la conducta de los Estados frente a inversiones protegidas por el Derecho Internacional. Adicionalmente, en el texto de los Tratados Internacionales de Protección Recíproca de Inversiones se incluye un capítulo específico de sujeción a un arbitraje internacional como la instancia que juzgará con imparcialidad e independencia y precautelará la confianza de sujetos privados extranjeros que pueden verse afectados por las decisiones de los Estados. La 
limitación que en términos de imparcialidad o independencia podría encontrarse en los tribunales domésticos hace que los inversionistas busquen instancias impermeables a la presión del poder político e imperturbables frente a las coerciones mediáticas de cada país.

Los tribunales de arbitraje del CIADI o de aquellos que se constituyen bajo las reglas UNCITRAL constituyen en mi opinión una apropiada alternativa para garantizar aquellas imparcialidad e independencia, consustanciales a la tarea de juzgar y de definir el derecho de partes en conflicto.

\section{LA TRADICIÓN JURÍDICA CIVILISTA FRENTE AL NUEVO DERECHO INTERNACIONAL DE LAS INVERSIONES}

Lo expuesto en el presente análisis pretende destacar ciertos aspectos que definen a los ordenamientos jurídicos de nuestros países latinoamericanos. A continuación identificaré los puntos de conflicto que considero más relevantes en los que habrá que seguir reflexionando para afirmar, aún más, el régimen de solución de conflictos a cargo de tribunales arbitrales internacionales.

\section{a) La concepción del derecho y la justicia}

Una diferencia fundamental podríamos destacar entre la familia jurídica romano germánica frente a la del common law: la primera tiene como su preocupación inmediata sentar las bases del orden social mientras que la segunda, con objetivos más modestos, se propone solamente restablecer la justicia en cada conflicto sometido a la decisión de los jueces.

De ahí que tanto en el sistema del common law como en el orden angloamericano el papel creador del derecho asignado a los jueces tenga una importancia superlativa y en esto hay un

Revista Ecuatorlana de ARritritaje 
aporte sustancial a la forma cómo se desenvuelven los mecanismos de solución de conflictos en el derecho internacional de las inversiones, en que los pronunciamientos que hacen los tribunales arbitrales tienen una importancia mayor que la asignada a la jurisprudencia en los sistemas romanistas cuya aspiración de justicia concede más importancia a la definición de voluntad general que hace el legislador al expedir una ley.

\section{b) EI sistema de fuentes del derecho}

Un segundo elemento conflictivo deriva del anterior y viene dado por el sistema de fuentes. A contrapunto de los regímenes jurídicos basados en el Código Civil, el common law asigna una importancia específica a la costumbre. El derecho internacional de las inversiones también se sustenta en la costumbre internacional, es decir, en prácticas inveteradas que han brotado espontáneamente del tráfico mercantil internacional y que, con el paso del tiempo, han sido recogidos en tratados bilaterales de inversión y en tratados de libre comercio.

Por tanto, no será la potestad ordenadora de un legislador que aspira a instituir la justicia a través de la expedición de normas de efectos generales, la que tenga asignada el monopolio en la creación del derecho, sino el reconocimiento de que en la interrelación de personas surgirá espontáneamente un orden que respetará al derecho y que ese orden espontáneo irá configurando, con la práctica diaria, un minimun de principios tendientes a proteger la seguridad jurídica, la propiedad y la buena fe. Estos son los bienes jurídicos que el derecho de las inversiones va a proteger.

En consecuencia, los estándares de protección que integran el derecho internacional de las inversiones nos recuerdan que no es factible que un legislador lo prevea, lo regule y lo resuelva todo; que la justicia no se alcanza a través de un proyecto de ingeniera social expresado en leyes; y que en la expedición de un 
Código no se puede agotar la razón ordenadora de las relaciones humanas, menos aún, la dinámica de las transacciones mercantiles en un mundo cambiante y globalizado. Serán los árbitros internacionales los que en cada caso crearán el derecho y definirán si se ha violentado o no un estándar mínimo de protección, según las alegaciones y las pruebas aportadas por las partes.

\section{c) Litigios contra el estado}

En el territorio de un Estado soberano, todos sus habitantes, nacionales y extranjeros, están sometidos al ordenamiento jurídico de ese Estado y la ignorancia de la ley no excusa a persona alguna. Así es como se estructuraron sistemas jurídicos basados en leyes creadas por el Estado y la cultura jurídica de nuestros países latinoamericanos ha erigido a este respecto al menos cuatro postulados: el Derecho se reduce a la ley formalmente vigente; la voluntad general expresada en la ley será, a su vez, expresión de lo justo; el Estado está investido de prerrogativas porque promueve el bien común y deberá reconocérsele un conjunto de potestades y privilegios; se crean distinciones entre normas de Derecho Privado y de Derecho Público.

Aquí surge un tercer punto de conflicto que tiene relación con el arbitraje de inversiones, porque la decisión de un panel arbitral internacional, con seguridad se referirá a los institutos del Derecho Público interno de esos Estados, es decir a normas consustanciales a su tradición jurídica y muy caras a la sensibilidad de sus operadores legales.

Y ahí aparece la desconfianza de los Estados que consideran invadidos sus sistemas procesales a los que suelen considerar de "orden público", porque perciben que sus potestades soberanas están siendo rebasadas por tribunales arbitrales extranjeros cuando éstos disponen la adopción de medidas cautelares o resuelven controversias condenándolos a satisfacer cuantiosas indemnizaciones. 
Para resolver conflictos en el ámbito del derecho público, los Estados de tradición jurídica románica han creado órganos especializados en lo contencioso administrativo con potestades jurisdiccionales exclusivas y excluyentes y por ese motivo, para muchos deviene inexplicable la existencia de otros órganos, más aún, arbitrales extranjeros, que fiscalicen y hagan valoraciones jurídicas sobre materias relacionadas con actuaciones de un Estado soberano.

Las controversias entre inversionistas y Estados bien podrían ventilarse ante los órganos contencioso administrativos - nos dirán-, más aún si los contratos que vinculan a esas partes son de carácter administrativo y las declaraciones de voluntad que hace el Estado a través de reglamentos y de actos administrativos están sujetas a los principios del derecho administrativo.

El derecho internacional de las inversiones nos recuerda que los compromisos asumidos por el Estado, con relación a inversionistas extranjeros, comportan obligaciones internacionales y que, por mandato de la Convención de Viena sobre el Derecho de los Tratados, los Estados no pueden invocar las normas de su derecho interno para incumplir tales obligaciones ${ }^{8}$.

\section{d) El sistema procesal y la práctica de pruebas instrumentales y testimoniales}

En un litigio arbitral internacional también contradicen los sistemas probatorios: por un lado se practican pruebas bajo el sistema de obtención y revelación de documentos discovery del régimen angloamericano, frente a los métodos inquisitoriales que hacen parte de la tradición civilista adoptada en la mayoría de los códigos procesales de América Latina.

8. Convención de Viena sobre el Derecho de los Tratados: "Art. 27.- El Derecho Interno y la observancia de los tratados: Una parte no podrá invocar las disposiciones de su derecho interno como justificación del incumplimiento de un tratado. Esta notma se entenderá sin perjuicio de lo dispuesto en el art. 46". 
En este tema es particularmente importante en la tramitación de una controversia arbitral para revelar un documento o reexaminar un testigo, más aún cuando se ha difundido la tesis de la "deslocalización del arbitraje" en virtud de la cual un panel arbitral no está sujeto a ninguna ley adjetiva y, en consecuencia está autorizado para aplicar las normas procesales que estime más apropiadas al caso concreto 9 .

\section{PROCESOS DE ELABORACIÓN DE LAS REGLAS LEGALES}

Una vez que los principios jurídicos originados en la costumbre internacional han venido plasmándose en tratados de protección de inversiones, ¿podríamos concluir que el derecho internacional de las inversiones ha abrazado el positivismo legalista presente en la organización jurídica de nuestros Estados latinoamericanos?

En mi opinión esa podría ser una conclusión extrema, porque supondría que todo derecho solamente podrá fundamentarse en la norma escrita de un tratado.

Frente a este fenómeno, una conclusión atenuada, pero más objetiva, sería que el derecho internacional de las inversiones tiene un punto de aproximación con los sistemas de tradición románica a partir de la consagración de sus principios en normas escritas, nada más.

Por ello es necesario enfatizar que este acercamiento hacia la codificación de reglas de protección en tratados bilaterales presenta algunos matices. La técnica adoptada en los procesos de elaboración de las normas en los tratados de protección recípro-

9. Sobre el tema existe un interesante análisis de Pedro J. Martínez Fraga titulado "La obtención y revelación de documentos e infornación en el proceso civil estadounidense (Discovery) y su influencia en la convergencia de culturas juridicas en el arbitraje internacional", Revista Penuana de Arbitraje No. 8, Lima, 2009 pp. 5 J-101. 
ca de las inversiones también es cercana a cómo se organiza el sistema del common law, sin quedar tampoco cobijada bajo la sombra de este sistema.

La escuela del Análisis Económico del Derecho ha establecido que existen distintas formas en que pueden desarrollarse la tarea legislativa y los contenidos de la norma de derecho. Según las reflexiones de Richard Posner ${ }^{10}$, catedrático de la Universidad de Chicago y Juez del Tribunal de Apelaciones del Séptimo Circuito, el legislador puede optar por el "método estatutario" en que el mismo asume mayor responsabilidad para definir con precisión el contenido de las reglas que dicta, o puede optar por el "método del estándar" que, a diferencia del anterior, exige de los jueces un trabajo preponderante para la formulación de reglas.

El "método estatutario", adoptado en regímenes de tradición civilista produce normas sobrecargada de requisitos, de condicionantes y de preceptos que procuran agotar hipótesis y que deben cumplirse para poder obtener el objetivo que la imaginación del legislador se propuso alcanzar.

Por su parte, el "método del estándar" se conforma con la enunciación de un concepto jurídico indeterminado y es utilizado por todos los tratados de protección de inversiones, que se han limitado a establecer un parámetro para que sea la apreciación del juzgador la que establezca en cada caso si la conducta de que se trate se encuadra o no en dicho parámetro cumpliéndolo o transgrediéndolo. Ejemplos de esos conceptos jurídicos indeterminados son: trato nacional, tratamiento de la nación más favorecida, trato justo y equitativo, no confiscación, libre transferencia de fondos y dividendos.

Los operadores jurídicos de nuestros sistemas, abogados, jueces, legisladores, académicos que nos hemos formado bajo los

10. Richard A. Posner, "El Análisis Económico del Derecho", Ed. Fondo de Cultura Económico, México D.F., $2^{a}$. ed. en español, 2007, pp. 836 a 842. 
cánones de un sistema de Derecho que abraza la tradición codificadora civilista y el positivismo kelseniano, tenemos una mayor inclinación por el método estatutario, y por tradición hemos reducido el fenómeno jurídico o un fenómeno social a la letra de una ley detallada porque semejante método aporta, aparentemente, mayor seguridad y certeza. Bajo una concepción hegeliana que considera al Estado como la encarnación del espíritu ético, será la soberbia de la voluntad ordenadora de un legislador la que le lleve a pensar que en su imaginación pueden quedar resueltas todas las posibilidades que la diversidad humana plantea, y para ello expedirá normas y más normas y no se cansará de crear y recrear instituciones jurídicas, ordenándolas en un código.

Por su parte, el "método estándar" o del "concepto jurídico indeterminado" que emplean los tratados de protección de las inversiones y que constituyen la materia sobre la que se pronunciarán los tribunales internacionales de arbitraje, con posiciones más modestas, confía en el papel creador del juez, en la lógica que éste emplee y en su sentido de la justicia para resolver apropiadamente el caso partiendo de circunstancias específicas, a fin de establecer si el hecho concreto está o no dentro del concepto jurídico indeterminado, dentro del estándar o principio enunciado por la norma o por la costumbre.

El "método estándar" es menos rígido que el "método estatutario", pero sin lugar a dudas presenta mejores condiciones para adaptarse a la dinámica de la realidad; y en un mundo altamente competitivo, en que la globalización de los mercados interrelaciona inversionistas privados y Estados con una mayor intensidad, es de suponer que el índice de conflictividad tenderá a incrementar y que ante ello los arbitrajes de inversión deben presentar condiciones de mayor adaptabilidad a la conflictividad creciente entre los intereses contradictorios de inversionistas extranjeros y Estados receptores de inversiones. 
En el análisis económico de los métodos legislativos, Francisco González de Cossio ha destacado al menos cuatro razones que se deben tener presente para optar por uno $u$ otro método: $(i)$ costo de negociación de la norma al que prefiero llamarlo costo de promulgación; (ii) costos de agencia para controlar su efectiva aplicación; (iii) depreciación de la regla relativa a la vigencia de la norma como fuente de derechos; y, (iv) eficacia y observancia ${ }^{11}$

a) PROCESO DE PROMULGACIÓN. El método del principio enunciado facilita el consenso en cuanto a su contenido porque el concepto indeterminado se limita a precautelar un valor jurídico. Los tratados de protección de inversiones que precautelan estándares de no confiscación, no discriminación, trato justo y equitativo, no abundan en la regulación de qué se entiende por tales preceptos, y trasladan la dificultad de definir sus contenidos a los tribunales arbitrales que conocerán de una disputa de inversiones.

El método estatutario presenta dificultades para alcanzar el consenso entre quienes aprueban la norma, porque en la aspiración de detallar su contenido aflorarán múltiples intereses, aun cuando su ejecución pueda resultar más fácil porque el juzgador o el funcionario administrativo se limitarán a establecer si los hechos están o no comprendidos dentro de la norma legal y de la casuística de la norma.

b) COSTOS DE AGENCIA: Así es como Posner identifica la aplicación práctica del método estatutario o reglamentario que permite un mayor control y arroja una mayor certidumbre en la observancia de la norma. Sin embargo, como destaca Francisco González de Cossío, en la práctica, el método del prin-

11. En este análisis adeudo la contribución doctrinal de Richarơ Posner en su obra Análisis Económico del Derecho y la sintesis de Francisco González de Cossío en un interesante artículo titulado "Medidas equivalentes a Expropiación en Atbitrajes de Inversión", publicado en la Revista Internacional de Arbitraje No. 4, enero-junio 2006, E. Univerșidad Sergio Arboleda, Comité Colombiano de Arbitraje y LEGIS, Bogotá Colombia, páginas 169 a 172. 
cipio enunciado se ha revelado más eficaz para lograr los fines últimos que se propuso alcanzar la norma.

c) DEPRECIACIÓN DE LAS REGLAS: La vigencia de la norma es un aspecto fundamental porque bajo el método legislativo que adoptan los tratados de protección de inversiones, sus contenidos resultan impermeables al paso del tiempo puesto que corresponderá a la jurisprudencia de los tribunales arbitrales internacionales el papel de adaptar el estándar a las cambiantes circunstancias de la realidad.

Las reglas detalladas, como las que existen en nuestros sistemas legales, tienden a la obsolescencia en períodos relativamente breves y generan otro tipo de dificultad cuando las normas derogadas por la realidad quedan formalmente vigentes en nuestros sistemas legales, generando pérdida de confianza y vaciando de contenido a la seguridad jurídica.

d) EFICACIA DEL DERECHO. Sobre este punto, hago mías las conclusiones de Francisco González de Cossío que precisa cuatro aspectos a tener en cuenta: el primero es más fácil observar una regla que un estándar; el segundo, la observancia de la regla brinda mayor seguridad que la del estándar; el tercero, la reglamentación vía estándar es más proclive a lograr los fines últimos que se propone la norma; y el cuarto, que con los estándares, la determinación del cumplimiento es ex post facto ${ }^{12}$.

Como se puede apreciar, el método de legislación al que Posner denomina "estatutario" y que adoptan nuestros países en la estructuración de sus sistemas legales es radicalmente diferente al "método estándar" o del principio enunciado que caracteriza a la técnica de legislación de los tratados de protección recíproca de inversiones. El primero, el método estatutario, privilegia la certeza de una normativa lo suficientemente desarrollada para alcanzar seguridad. Pero es una seguridad sobre la

12. Francisco González đe Cossío, op. cit. p. 171. 
regulación declarativa de una norma y que muchas veces se desentiende de la eficacia de su aplicación.

\section{Conclusiones}

1. La globalización de la economía nos demuestra, por un lado, que el tráfico mercantil integra con mayor eficacia economías y tecnologías y, por otro, que la integración de los sistemas jurídicos no opera con la misma dinámica. Sin embargo, la intensificación del comercio y del flujo de las inversiones, ha impulsado una suerte de convergencia entre regímenes de tradición jurídica diversa.

2. La denominada "globalización" nos avoca a otras maneras de entender y aplicar el derecho porque vincula no solamente economías sino regímenes jurídicos y en ese acercamiento de las familias del Derecho se aprecia que la costumbre mercantil internacional y la jurisprudencia desempeñan un papel protagónico para definir el alcance de los estándares de protección a las inversiones, distinto al que le asignan nuestros sistemas de tradición civilista.

3. El derecho internacional de las inversiones es el producto de una confluencia de tradiciones jurídicas expresadas en estándares de protección a la inversión extranjera como son la no discriminación, el trato justo y equitativo, la no confiscación, la cláusula de la nación más favorecida, el trato nacional, todos ellos orientados a precautelar el derecho natural a la seguridad jurídica, el principio universal de buena fe y el derecho humano fundamental a la propiedad. Estos estándares nacidos de la costumbre y de prácticas inveteradas han sido recogidos en tratados de protección de inversiones y en capítulos específicos de los denominados tratados de libre comercio.

4. Los operadores legales no podemos permanecer indiferentes frente a este proceso y debemos profundizar en los cinco 
puntos de conflicto que han quedado mencionados para facilitar la convergencia de los regímenes legales: concepción del derecho, sistema de fuentes, reglas de procedimiento y actuación de pruebas y, proceso de elaboración de reglas. En este tema es indispensable hacer un análisis costo / beneficio de los diversos institutos jurídicos involucrados en una controversia arbitral internacional, principalmente, de los estándares de protección de las inversiones. Se hace necesario también valorar el aporte de la costumbre como fuente de las instituciones mercantiles y reflexionar sobre los vicios del positivismo analítico que reduce el fenómeno jurídico a la letra de la ley.

5. Los tribunales arbitrales internacionales que conocen de controversias relativas a inversiones, de alguna manera hacen posible esta integración jurídica a fin de que el Derecho y los ideales de justicia que podrían diferir según sea la cultura que los aplica, no pierdan el compás marcado por la dinámica del intercambio mercantil y no se aparten de los fundamentos del derecho natural. Aun con la existencia de laudos contradictorios, el sistema arbitral internacional tenderá a depurarse en cada caso que resuelva con el auxilio de la doctrina y de los abogados que litigan.

6. El derecho internacional de las inversiones tenderá a crearse y a recrearse en la jurisprudencia de los tribunales arbitrales que se constituyan bajo el sistema CIADI o bajo las reglas UNCITRAL. Las culturas jurídicas que se comunican a través del arbitraje deben estar atentas a los brotes de incultura jurídica y de aculturación que no han tardado en aparecer para desmerecer al arbitraje internacional de inversiones y para ensimismar a los regímenes legales en un aislamiento injustificado en un mundo cada vez más interrelacionado. 